\title{
Government proposals for primary care: White hope, elephant, or sepulchre?
}

Last week's white paper on primary care has the praiseworthy aims of upgrading standards, improving the service to patients, and increasing efficiency. The detailed proposals are summarised on p 1497, and at first sight they look like the biggest advance in primary care since the Family Doctor Charter of 1966. The white paper has incorporated many of the suggestions made by people and organisations striving to improve general practice. But is the balance of proposals right and how will the financial implications be managed?

The need to shift work from expensive, often impersonal, tertiary and secondary care to the cheaper more human care of general practice is internationally recognised, and the white paper introduces proposals to this end. It emphasises undergraduate and continuing education to prepare for and build on mandatory vocational training. Even more important is the recognition that doctors need to delegate work to specially trained ancillary staff, particularly nurses, and the removal of restrictions on the numbers of ancillary staff eligible for reimbursement must be welcomed, especially as they will be allowed subsidised continuing education. Any increase in staff and their education will for the first time, however, be subject to financial limits, and we do not know how generous this provision will be.

Many of the proposals extend the provisions of the Family Doctor Charter, when enthusiastic practitioners seized on the offered advantages; the less enthusiastic ignored them, leading to a widening of the gap between the best and the poorest of general practice. The new proposals may be similarly divisive. It is sad that efforts at raising standards always seem to be aimed at the already good. Thus I welcome the rejection of the good practice allowance, which had been mooted in the previous discussion document, but despite the checks and systems of reward the new proposals still seem divisive. Increase in mean standards is best achieved by improving the less good; what is needed is extra payment for a bad practice paid only after audited deficiencies have been corrected.

The main worry for the general practitioner is that the new proposals may increase workload. The health education already widely, though insufficiently, offered takes time, especially when concentrated on children and the elderly. Screening and routine physical examination not only are time consuming but also can be dull. The absorption of work from hospitals, implied in better care of the chronic sick and reduction of regular outpatient appointments with often inexperienced junior staff, must also increase workload. Noticeably, the incipient threat of the acquired immune deficiency syndrome with its huge implications for primary care is dismissed in a mere seven lines.
How then will doctors cope with these imponderably large $\underset{\mathbb{D}}{\mathbb{D}}$ effects on their workload? The House of Commons social m

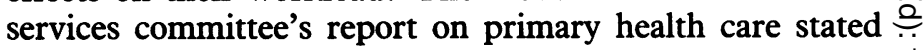
that the case for further reduction in list sizes was unanswerable, but the white paper has ignored this. Instead, the minimum list size is to be increased as will be the commitment of each general practitioner to spend at least 20 hours a $\frac{\bar{\sigma}}{5}$ week in contact with patients. At first sight this seems right $\stackrel{\mathbb{Q}}{\circ}$ (and a few doctors may have taken professional life very \& easily), but some doctors spend their time away from their. practices in hospital work, teaching, administration, or medicopolitics. Such functions are not only valuable in $\vec{\omega}$ themselves but also increase job satisfaction and provide a $\frac{D}{P}$ stimulus to improve. A stick applied to the less good may well 3 hurt the better most. Only through provisions for ancillary i⿱ staff does the government propose to meet the burden of or increased workload. Many doctors who have urged increased $\stackrel{\circ}{g}$ jobs for nurses in primary care will be delighted, but the $\overrightarrow{\overrightarrow{\vec{P}}}$ concept of the nurse practitioner with increased diagnostic $\vec{t}$ and therapeutic responsibilities is not yet generally accepted.

Governments have the unenviable task of keeping within budgets, and, as has become all too obvious in the recent $\stackrel{5}{\mathrm{o}}$ past, provision of health represents a bottomless financial pit. Doctors must fight to maintain standards while acknow- $\mathbb{D}^{\circ}$ ledging that the bills have to be paid. Yet the proposals $\stackrel{\oplus}{\rightrightarrows}$ for funding the white paper seem ludicrously inadequate. Raising funds by making economies in dental and ophthalmic services not only undermines the government's intention of better prevention but also is not enough. Perhaps the caravan sites on spare NHS land and fruit machines in every hospital foyer will help a little, but unless the government is realistic about funding the changes they will degeneratefirstly, into a white elephant of uselessness and then into a white sepulchre, the final resting place of one of Britain's greatest institutions, the National Health Service.

Macmillan Senior Lecturer in Palliative Care,

Department of General Practice,

Birmingham University Medical School, Birmingham B15 2TJ

\section{Correction}

Looking beyond oral rehydration therapy

We regret that an error occurred in the leading article by Dr G J Ebrahim (14 November, $p$ 1222). In the fourth paragraph Streptococcus stercoralis should have read Strongyloides stercoralis. \section{.}

